\title{
Produção de batata-doce adubada com esterco bovino em solo com bai- xo teor de matéria orgânica
}

\author{
João F dos Santos; Ademar P de Oliveira ${ }^{1}$; Adriana U Alves; Carlos H de Brito; Carina SM Dornelas; \\ José PR Nóbrega
}

UFPB, CCA, C. Postal 02, 58397-000 Areia-PB; E-mail: ademar@cca.ufpb.br; ${ }^{1}$ Bolsista em produtividade em pesquisa CNPq

\begin{abstract}
RESUMO
Com o objetivo de avaliar o efeito da adubação orgânica na produção total e comercial de raízes de batata-doce, cv. Rainha Branca, conduziu-se um experimento de junho a outubro de 2004, na UFPB, em Areia (PB). O delineamento experimental foi de blocos casualizados com seis tratamentos $\left(0 ; 10 ; 20 ; 30 ; 40\right.$ e $50 \mathrm{t} \mathrm{ha}^{-1} \mathrm{de}$ esterco bovino), em quatro repetições. As produções total e comercial de raízes de batata-doce foram de 18,5 e 14,2 $\mathrm{tha}^{-1}$, obtidas com 32 e $30 \mathrm{t} \mathrm{ha}^{-1}$ de esterco bovino. A dose de esterco bovino responsável pelo máximo retorno econômico para a produção de raízes comerciais $\left(30 \mathrm{t} \mathrm{ha}^{-1}\right)$, foi igual aquela que proporcionou a produção máxima, representando $100 \%$ da máxima eficiência técnica, constituindo um indicativo da viabilidade econômica do emprego de esterco bovino no cultivo da batata-doce. As doses estimadas de esterco bovino que resultaram na máxima produção de raízes comerciais e no máximo retorno econômico corresponderam com 13,8 g L de matéria orgânica presente no solo após a colheita. Em solos semelhantes ao deste estudo, a adubação orgânica na batata-doce poderá ser dispensada, quando o teor de matéria orgânica no solo for superior a $13,8 \mathrm{~g} \mathrm{~L}$ de solo.
\end{abstract}

Palavras-chave: Ipomoea batatas, adubação orgânica, produção de raízes.

\begin{abstract}
Production of sweet potato fertilized with cattle manure in soil with low organic matter content

The influence of organic fertilization on total and commercial production of sweet potato roots, Rainha Branca cv. was evaluated. The experiment was carried out from June to October/2004, in Paraiba State, Brazil. The experimental design was of randomized blocks with six treatments $\left(0 ; 10 ; 20 ; 30 ; 40\right.$ and $50 \mathrm{tha}^{-1}$ of cattle manure), in four replications. The total and commercial productions of sweet potato roots were 18.5 and $14.2 \mathrm{t} \mathrm{ha}^{-1}$ obtained with 32 and $30 \mathrm{t} \mathrm{ha}^{-1}$ of cattle manure. The cattle manure level responsible for maximum economic return of commercial roots $\left(30 \mathrm{tha}^{-1}\right)$, was equal to that which allowed maximum production, represented $100 \%$ of maximum technique efficiency, constituting an indicative of the economic viability of cattle manure application in sweet potato. The estimated cattle manure levels which resulted maximum production and economic returns for commercial roots, corresponded to $13.8 \mathrm{~g} \mathrm{~kg}^{-1}$ of remaining organic matter with the extractor. In similar soils of this study, the organic fertilization for sweet potato production can be dispensed, with remaining organic matter level higher than $13.8 \mathrm{~g} \mathrm{~kg}^{-1}$ of soil.
\end{abstract}

Keywords: Ipomoea batatas, organic fertilization, root production.

\section{(Recebido para publicação em 7 de junho de 2005; aceito em 10 de fevereiro de 2006)}

$\mathrm{N}$ a região Nordeste, a batata-doce tem grande importância social, por ser uma fonte de alimento energético, e auxiliar na geração de emprego e renda, contribuindo para a fixação do homem no campo. No estado da Paraíba, esta cultura é mais cultivada e difundida nas regiões próximas aos grandes centros consumidores, especialmente nas microrregiões do brejo e do litoral Paraibano, sendo esse estado considerado o maior produtor nordestino e o quarto produtor brasileiro (Soares et al., 2002). No entanto, tem uma das mais baixas produtividades do Brasil, 6,8 $\mathrm{t} \mathrm{ha}^{-1}$ (Silva et al., 2002). Esse fato é reflexo da ausência de tecnologia, informações e conhecimentos adequados principalmente com relação à fertilização orgânica e mineral, o que tem provocado perda de receita desestimulando os produtores e contribuído para o decréscimo da área plantada.
A batata-doce possui um sistema radicular muito ramificado, com alta capacidade de exploração do solo, o que a torna eficiente na absorção de nutrientes. Entretanto, esta característica leva a um rápido esgotamento da reserva de nutrientes do solo, o que induz os produtores a cultivarem preferencialmente áreas novas, onde normalmente, há maior disponibilidade de nutrientes, dispensando a adição de fertilizantes. Por outro lado, quando o solo apresenta fertilidade inadequada para a cultura, se faz necessário o uso da adubação (Pimentel, 1985; Silva et al., 2002).

A resposta da batata-doce à adubação depende das condições do solo. Quando cultivada em solos com fertilidade natural média a alta, geralmente não há resposta à adubação, mas em solos pouco férteis o uso de fertilizantes minerais e orgânicos, proporciona incremento significativo na produtivi- dade (Monteiro et al., 1997). Contudo, em solos com alta disponibilidade de nutrientes ocorre intenso crescimento da parte aérea, em detrimento da formação de raízes tuberosas, sendo que as cultivares respondem de modo distinto à aplicação de nutrientes. Enquanto algumas apresentam grande desenvolvimento de tubérculos, outras apresentam crescimento vegetativo exuberante (Chaves \& Pereira, 1985).

De forma geral, quando aplicados corretamente, os nutrientes podem ocasionar boas respostas na batata-doce (Filgueira, 2000). Nesse sentido, Mendonça \& Peixoto (1991) obtiveram respostas significativas para a produtividade, produção por planta e peso médio de raízes comerciais de batata-doce, em função do emprego de fertilizantes orgânicos e minerais; enquanto Oliveira et al. (1980) observaram, em solo aluvial de leito de rios, que o consórcio de fei- 
jão-caupi com batata-doce pode ser inviabilizado, caso não sejam utilizadas de 20 a 40 t ha $^{-1}$ de esterco bovino.

A nutrição deficiente das plantas de batata-doce pode causar abscisão das folhas (Chaves; Pereira, 1985); induzir a produção de tubérculos pequenos, com baixa aceitação no mercado (Monteiro et al., 1997); provocar atraso no crescimento; reduzir a acumulação de amido e de glicose nos tubérculos e alterar características importantes no armazenamento, como textura e firmeza dos tubérculos (Chaves \& Pereira, 1985).

Face o exposto, o presente trabalho teve como objetivo avaliar o efeito da aplicação de doses de esterco sobre a produção de raízes de batata-doce.

\section{MATERIAL E MÉTODOS}

O trabalho foi conduzido na área experimental do CCA da UFPB, em Areia, entre junho e outubro de 2004, período do plantio à colheita. Foi utilizado o delineamento experimental de blocos casualizados, com seis tratamentos, representados pelas doses de $0 ; 10$; 20; 30; 40 e $50 \mathrm{t} \mathrm{ha}^{-1}$ de esterco bovino, e quatro repetições. O solo da área experimental foi classificado como NEOSSOLO REGOLITICO Psamítico típico, textura areia-franco. A área experimental foi preparada por meio de aração, gradagem e construção de leirões de aproximadamente $30 \mathrm{~cm}$ de altura. A parcela foi composta por 56 plantas, dispostas em sete leirões com oito plantas cada, espaçadas de $0,80 \mathrm{~m}$ entre leirões e de 0,30 m entre plantas.

Amostras do solo foram retiradas da camada de $0-20 \mathrm{~cm}$ e as análises químicas e físicas revelaram: $\mathrm{pH}\left(\mathrm{H}_{2} \mathrm{O}\right)=5,7$; $\mathrm{Al}^{+++}=0,00 \mathrm{cmol} \mathrm{dm} \mathrm{dm}^{-3} \mathrm{Ca}^{++}=2,25$ $\mathrm{cmol}_{\mathrm{c}} \mathrm{dm}^{-3} ; \mathrm{Mg}^{++}=1,05 \mathrm{~mol}_{\mathrm{c}} \mathrm{dm}^{-3} ; \mathrm{P}=$ $21,8 \mathrm{mg} \mathrm{dm}^{-3} ; \mathrm{K}^{+}=54,81 \mathrm{mg} \mathrm{dm}^{-3}$; matéria orgânica $=12,68 \mathrm{~g} \mathrm{dm}^{-3}$; areia gros$\mathrm{sa}=672 \mathrm{~g} \mathrm{~kg}^{-1}$; areia fina $=125 \mathrm{~g} \mathrm{~kg}^{-1}$; silte $=126 \mathrm{~g} \mathrm{~kg}^{-1}$; argila $=77 \mathrm{~g} \mathrm{~kg}^{-1}$; densidade do solo $=1,28 \mathrm{~g} \mathrm{~cm}^{-3}$. A caracterização química do esterco bovino revelou os seguintes teores em $\mathrm{g} \mathrm{kg}^{-1}$ de matéria seca: $\mathrm{P}=5,2 ; \mathrm{K}=4,90 ; \mathrm{N}=8,82 \mathrm{e}$ matéria orgânica $=112,07 \mathrm{~g} \mathrm{dm}^{-3}$.

A adubação constou apenas da aplicação das doses de esterco bovino definidas no delineamento, as quais foram incorporadas nos leirões quinze dias antes do plantio. No plantio, foram utilizadas ramas da cultivar Rainha Branca, batata de boa aceitação comercial na região, retiradas de plantio jovem, em área próxima ao experimento. As ramas foram cortadas com um dia de antecedência ao plantio, para facilitar o manejo, e seccionadas em pedaços de aproximadamente $40 \mathrm{~cm}$ de comprimento, contendo em média oito entrenós. As ramas foram enterradas pela base, com auxílio de um pequeno gancho, na profundidade de 10 a $12 \mathrm{~cm}$.

Durante a condução do experimento foram realizadas irrigações pelo sistema de aspersão nos períodos de ausência de precipitação, com turno de rega de três dias; capinas manuais, com auxílio de enxada, para manter a cultura livre de competição com plantas daninhas; e amontoas, para proteger as raízes contra a incidência de luz e manter a formação dos leirões.

A colheita foi realizada aos 120 dias após o plantio, quantificando-se as produções total e comercial de raízes. A produção total correspondeu ao peso de todas as raízes colhidas; enquanto a comercial, ao peso de raízes frescas, de formato uniforme e lisas e com peso igual ou superior a $80 \mathrm{~g}$, conforme descrito em Embrapa (1995).

Os dados foram submetidos à análise de variância e de regressão. Modelos polinomiais foram testados para prever os efeitos de doses de esterco bovino sobre os atributos avaliados. $\mathrm{O}$ critério para escolha do modelo mais adequado foi a significância pelo teste $\mathrm{F}$ a $5 \%$ de probabilidade e o maior valor do coeficiente de determinação $\left(\mathrm{R}^{2}\right)$. Ao final da colheita efetuou-se nova amostragem do solo (0-20 $\mathrm{cm}$ de profundidade), coletando-se dez amostras simples ao acaso por parcela para se determinar o teor de matéria orgânica presente no solo após a colheita pelo método de oxidação via úmida com dicromato de potássio, em meio sulfúrico (Embrapa, 1997).

A partir do ajuste das equações, calculou-se a dose de esterco bovino que proporcionou a produção máxima econômica de raízes comerciais. Para minimizar os efeitos da variação cambial, empregou-se uma relação de troca ao invés de moeda corrente, igualando- se a derivada segunda às relações entre preço do produto e do insumo (Raij, 1991; Natale et al., 1996), vigentes em Areia-PB, em 2004. Buscou-se assim, dados mais estáveis, pela relação de dy/ $d x=a_{1}+2 a_{2} x$. A dose mais econômica (x') foi calculada pela equação:

\section{$x^{\prime}=a_{1}$ - relação de equivalência

$$
2\left(-a_{2}\right)
$$

Neste estudo, os valores utilizados para as variáveis raízes comerciais e esterco bovino, foram, respectivamente, $\mathrm{R} \$ 0,50 / \mathrm{kg}$ e $\mathrm{R} \$ 0,05 / \mathrm{kg}$. Dessa maneira, a 'moeda' utilizada nos cálculos da dose econômica de esterco bovino foi a própria raiz. Assim, a relação de equivalência entre o quilograma do insumo e o quilograma de raízes foi igual a 0,1 , porém, essa relação de preços pode variar a cada ano, conforme a demanda e a oferta.

\section{RESULTADOS E DISCUSSÃO}

Houve efeito significativo $(\mathrm{p}<0,01)$ dos tratamentos sobre as produções total e comercial de raízes de batata-doce e sobre o teor de matéria orgânica presente no solo após a colheita. Modelos quadrático e linear foram empregados para prever os efeitos da adubação orgânica sobre, respectivamente, as produções total e comercial de raízes e de matéria orgânica residual no solo.

As produções máximas total e comercial de raízes estimadas, pelos modelos, foram 18,5 e 14,2 $\mathrm{t} \mathrm{ha}^{-1}$, obtidas, respectivamente, com 32 e $30 \mathrm{t} \mathrm{ha}^{-1} \mathrm{de}$ esterco bovino (Figura 1). Essas produções resultaram incrementos de 9,85 e $8,62 \mathrm{t} \mathrm{ha}^{-1}$ de raízes, respectivamente, que corresponderam a ganhos de, respectivamente, 112 e $154 \%$ em relação às produções obtidas na ausência de adubação com esterco bovino. Destacase também que a produção máxima de raízes comerciais superou em $7,4 \mathrm{t} \mathrm{ha}^{-1}$ a produtividade média do estado da Paraíba, calculada em 6,8 tha-1 (Silva et al., 2002) e em 4,2 t ha-1 a média nacional, descrita por Soares et al. (2002) em 10,0 t ha $^{-1}$.

Considerando que o solo da área experimental apresentava teor de maté- 


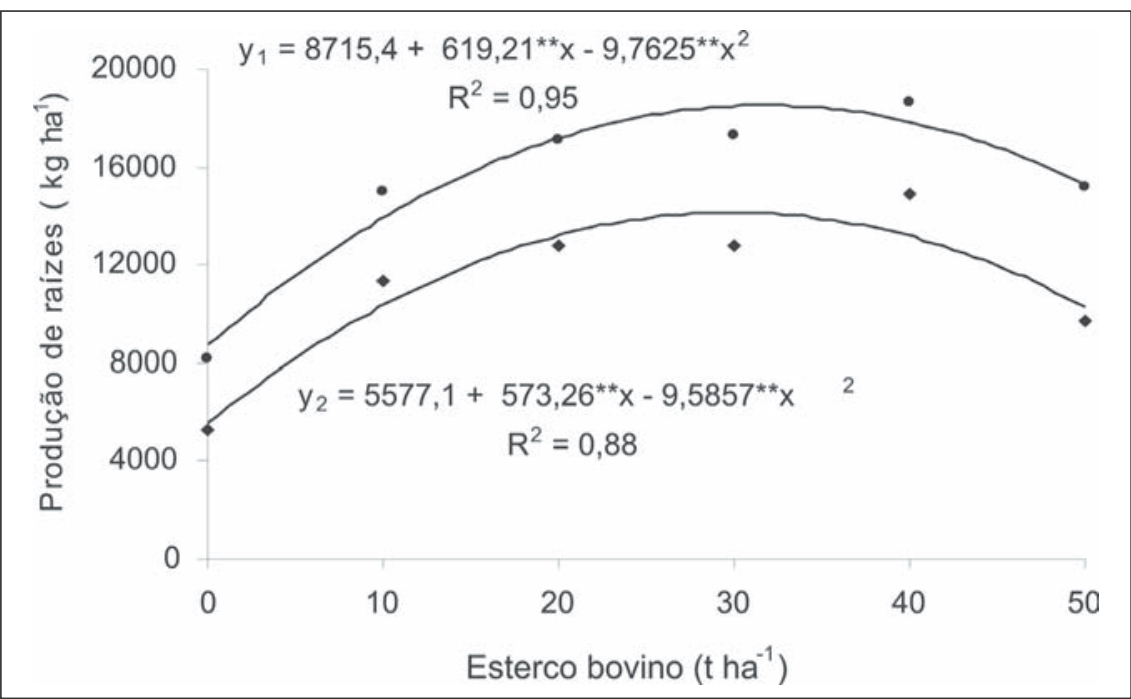

Figura 1. Produção total $\left(\mathrm{y}_{1}\right)$ e comercial $\left(\mathrm{y}_{2}\right)$ de raízes de batata-doce, em função de doses de esterco bovino. Areia (PB), CCA-UFPB, 2005.

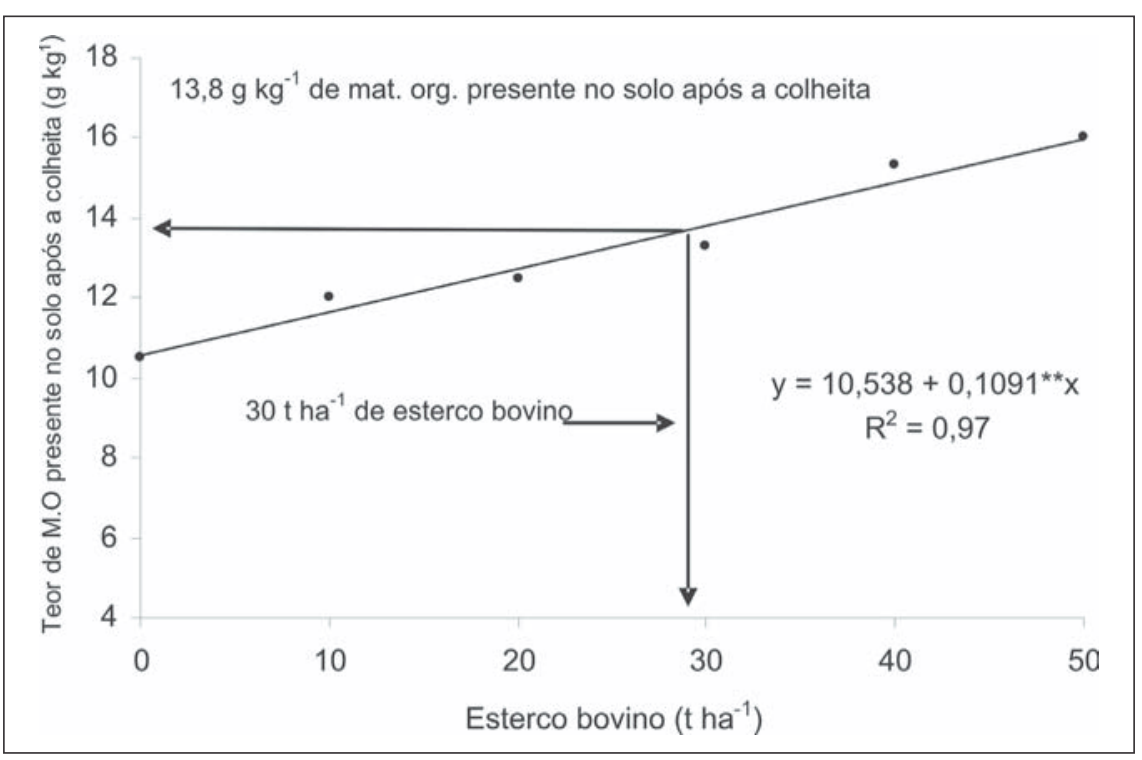

Figura 2. Teor de matéria orgânica presente no solo após a colheita, em função de doses de esterco bovino para o estabelecimento de batata-doce cultivar Rainha Branca, em Neossolo Regolítico Psamítico típico textura areia-franco. Areia (PB), CCA-UFPB, 2005.

ria orgânica de $12,68 \mathrm{~g} \mathrm{dm}^{-3}$, os resultados positivos obtidos em função do emprego do esterco bovino, possivelmente estão relacionados ao papel preponderante da matéria orgânica no fornecimento de nutrientes; na elevação da umidade do solo; na melhoria de sua estrutura; e no aumento da capacidade de troca catiônica, por meio da formação de complexos húmus-argila (Marchesini et al. 1988; Yamada; Kamata, 1989), proporcionando melhor aproveitamento dos nutrientes originalmente presentes. batata-doce, especialmente os estercos de animais, traduz-se no aumento de produção de raízes.

A estabilização e queda no rendimento acima das doses de esterco bovino, responsáveis pelas máximas produções de raízes, podem ser oriundas do excesso de nutrientes fornecidos à cultura, proporcionando crescimento excessivo das ramas, em detrimento da formação de raízes tuberosas, como relatado por (Chaves \& Pereira, 1985). Essas doses podem também ter sido responsáveis pelo aumento dos teores de nitrogênio e água no tecido vegetal acima do ótimo da cultura e provocado aumento nos teores de sais solúveis do solo, acarretando elevação da condutividade elétrica, desbalanço nutricional, com impacto negativo na produtividade raízes tuberosas (Silva et al., 2000).

$\mathrm{Na}$ dose de esterco bovino que correspondeu à máxima produção comercial de raízes, o teor de matéria orgânica presente no solo após a colheita foi de 13,8 $\mathrm{g} \mathrm{dm}^{-3}$ (Figura 2), muito próximo daquele inicialmente presente no solo $\left(12,68 \mathrm{~g} \mathrm{dm}^{-3}\right)$. Isto pode indicar que provavelmente, toda a matéria orgânica adicionada pela dose correspondente à máxima produção comercial de raízes, foi decomposta durante o ciclo da batata-doce. Portanto, pode-se inferir que esta matéria orgânica foi responsável por certo fornecimento de nutrientes e pela melhoria das condições físicas do solo e que a utilização do esterco bovino, em condições semelhantes as do presente estudo traz benefícios à sua produção.

A curva de resposta da produção comercial de raízes em função da aplicação do esterco bovino, foi como anteriormente destacado, de natureza quadrática (Figura 1). Utilizando-se os valores obtidos a partir da equação de regressão e com base na recomendação de Raij (1991), Natale et al. (1996) e Tavares Sobrinho (2001), calculou-se a dose mais econômica de esterco bovino pela equação:

$$
\begin{gathered}
\text { Dose de esterco bovino }\left(\mathrm{t} \mathrm{ha}^{-1}\right)= \\
\mathbf{5 7 3 , 2 6 - 0 , 1}=\mathbf{3 0}
\end{gathered}
$$


De acordo com Natale et al. (1996), a dose mais econômica, que define a quantidade de fertilizantes, ou de um nutriente específico, a se aplicar para a obtenção de receita máxima por área, corresponde ao ponto em que a quantidade aplicada proporciona a máxima distância entre a linha de custo do insumo e a curva de resposta. Por outro lado, a máxima eficiência técnica M.E.T. (obtida ao igualar a primeira derivada a zero), representa a dose de fertilizante em que a resposta da produção atinge o máximo. No caso deste trabalho, a dose econômica foi $30 \mathrm{t} \mathrm{ha}^{-1}$ de esterco bovino.

A receita prevista devido à utilização do esterco pode ser calculada pelo aumento de produção proporcionado pela dose econômica, custo do fertilizante e pela receita obtida. Igualandose a derivada primeira a zero, pode-se calcular o aumento de produção proporcionado pelo esterco bovino. Portanto, o insumo proporcionou aumento de 8,57 $\mathrm{t}$ ha ${ }^{1}$. Deduzindo-se o custo de aquisição de $30 \mathrm{t} \mathrm{ha}^{-1}$ de esterco bovino, equivalente a 3,0 t de raízes, obteve-se uma receita prevista de $5,57 \mathrm{t} \mathrm{ha}^{-1}$ de raízes comerciais.

A dose econômica foi igual a dose estimada para obtenção da produção máxima de raízes comerciais, representando $100 \%$ da M.E.T, demonstrando a viabilidade econômica da produção de batata-doce, considerando os índices empregados neste trabalho, com o emprego da adubação orgânica realizada com esterco bovino, em solos com baixo teor de matéria orgânica.

\section{LITERATURA CITADA}

CHAVES LHG; PEREIRA HHG. 1985. Nutrição $e$ adubação de tubérculos. Campinas: Cargill, p. 46-67.

EMBRAPA. Centro Nacional de Pesquisa de Hortaliças. 1995. Cultivo da batata-doce (Ipomoea batatas (L.) Lam). 3. ed. Brasília: Ministério da Agricultura, do Abastecimento e Reforma Agrária, (EMBRAPA-CNPH. Instruções Técnicas, 7).

EMBRAPA. Serviço Nacional de Levantamento e Conservação do Solo. 1997. Manual de métodos de análise de solo. Rio de Janeiro: Ministério da Agricultura, $212 \mathrm{p}$.

FILGUEIRA FAR. 2000. Novo Manual de Olericultura: Agrotecnologia moderna na produção e comercialização de hortaliças. 2. ed. Viçosa: UFV, 402 p.

MACHADO MO; GOMES AS; TURATTI EAP; SILVEIRA JUNIOR P. 1983. Efeito da adubação orgânica e mineral na produção do arroz irrigado e nas propriedades químicas e físicas do solo de Pelotas. Pesquisa Agropecuária Brasileira, 18: 583-591.

MARCHESINI A; ALLIEVI L; COMOTTI E; FERRARI A. 1988. Long-term effects of quality compost treatment on soil. Plant and Soil, 106: 253-261.

MENDONCCAATC; PEIXOTO N. 1991. Efeitos do espaçamento e de níveis de adubação em cultivares de batata-doce. Horticultura Brasileira, 9: 80-82.
MONTEIRO FA; DECHEN AR; CARMELO QCA. 19971997. Nutrição mineral e qualidade de produtos agrícolas. In: ABEAS. Curso de nutrição mineral de plantas. Piracicaba: ABEASESALQ, $27 \mathrm{p}$

NATALE W; COUTINHO ELM; BOARETTO A; PEREIRA FM. 1996. Dose mais econômica de adubo nitrogenado para a goiabeira em formação. Horticultura Brasileira, 14: 196-199.

OLIVEIRA JF; HOLANDA JS; FERNANDES JB; LEITE LAS; OLIVEIRA GM. 1980. Niveis econômicos de adubação orgânica no cultivo de feijão Vigna e batata-doce, em leitos de rio. Caicó, EMBRAPA/UEPAE, 6 p. (comunicado Técnico, 4). PIMENTELAAMP. 1985. Olericultura no tropico úmido: hortaliças na Amazônia. São Paulo: Agronomia Ceres, $322 \mathrm{p}$.

RAIJ BV. 1991. Fertilidade do solo e adubação. Piracicaba. Ceres, 343 p.

SILVA FN; MAIA SSS; OLIVEIRA M. 2000. Doses de matéria orgânica na produtividade da cultura da alface em solo eutrófico na região de Mossoró, RN. Horticultura Brasileira, 18: 723724 (Suplemento).

SILVA JBC; LOPES CA; MAGALHÃES JS 2002. Cultura da batata-doce. In: CEREDA MP; Agricultura: Tuberosas amiláceas Latino Americanas, São Paulo: Cargill, 2: 449-503.

SOARES KT; MELO AS; MATIAS EC. 2002. A Cultura da batata-doce (Ipomoea batatas (L.) Lam). João Pessoa: EMEPA-PB, 26 p. (EMEPAPB. Documentos, 41).

TAVARES SOBRINHO J. 2001. Rendimento $e$ qualidade do feijão-vagem em função de doses e aplicação de nitrogênio, $56 \mathrm{f}$. (Tese mestrado), CCA, UFPB, Areia.

YAMADA H; KAMATA H. 1989. Agricultural technological evaluation of organic farming and gardening I. Effects of organic farming on yields of vegetables and soil physical and chemical properties. Bulletin of the Agricultural Research Institute of Kanagawa Prefecture, 130: 1-13. 